\title{
Dr. Dirk W. Lachenmeier (food chemist and toxicologist), CVUA Karlsruhe, Germany
}

Created by: Dirk W. Lachenmeier ${ }^{1}$

1, Chemisches und Veterinäruntersuchungsamt (CVUA) Karlsruhe, Weissenburger Strasse

3, 76187 Karlsruhe, Germany; lachenmeier@web.de

Version received: 13 March 2020

check for

updates

Dr. Dirk W. Lachenmeier is state-certified food chemist, toxicologist, director of the department of plant-based foods and co-head of the nuclear magnetic resonance (NMR) laboratory at Chemical and Veterinary Investigation Agency, Karlsruhe, Germany.

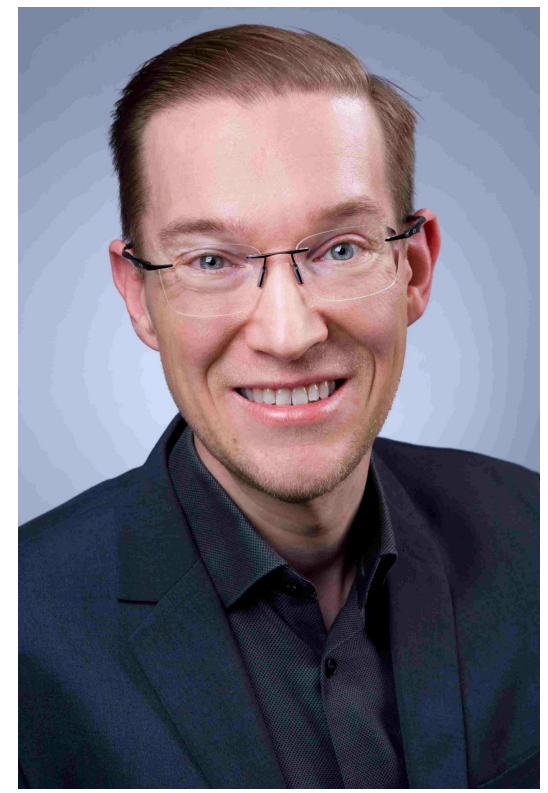

\section{Education}

Dr. Lachenmeier studied food chemistry (first state examination) at the University of Bonn (1994-1998), followed by position as first-year resident at various food control institutions in the State of North Rhine-Westfalia, concluding the studies with the second state examination and title of state-certified food chemist (Münster, 2000). He carried out his PhD in Forensic Toxicology at the Institute of Legal Medicine, University of Bonn (2000-2003). His PhD research included the development of an innovative methodology to detect cannabis and designer drugs in hair samples ${ }^{[1]}$.

\section{Career}

Since 2003, Dr. Lachenmeier is employed at the Chemical and Veterinary Investigation Agency Karlsruhe (CVUAKA), Germany, where he first headed the alcohol laboratory (2003-2012), and later was promoted as director of the department of plant-based food, where he is personally heading the Central State Coffee Control Laboratory and the Central State Cannabis Control Laboratory, and his group includes a team of scientists and technicians investigating various matrices such as tea, spices, bakery and pasta products, food supplements, and products for special nutritional demands (diets). At CVUAKA he also co-heads the nuclear mangetic resonance (NMR) laboratory since 2010 and his department is responsible for the fields "novel food products" and "internet trade". Dr. Lachenmeier has 
been working as official on secondment at the Ministry of Rural Affair and Consumer Protection Baden-Württemberg (2012-2013).

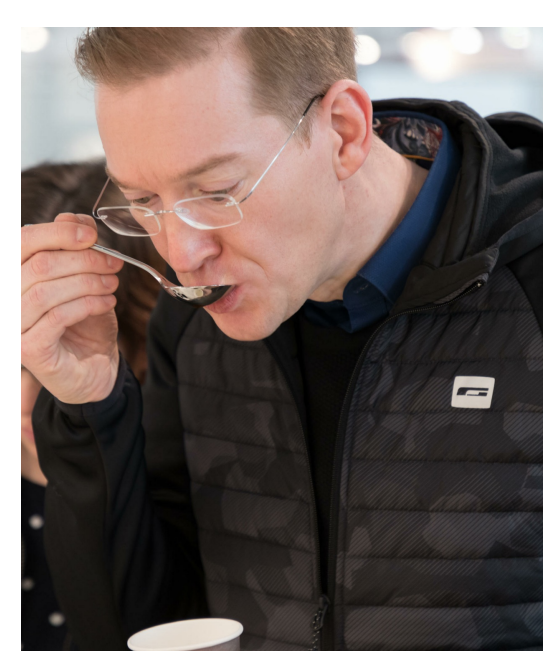

\section{Research Projects}

Apart from various in-house projects, Dr. Lachenmeier contributed to the EU FP7 projectsAMPHORA (Alcohol Measures for Public Health Research Alliance) (2009-2012) and ALICE-RAP (Addictions and Lifestyles In Contemporary Europe - Reframing Addictions Project) (2011-2016), for which he was avocationally working as scientist at the Institute of Clinical Psychology and Psychotherapy, Technical University of Dresden, Germany. The projects allowed Dr. Lachenmeier to achieve major conclusions on the composition and health risk of unrecorded alcohol, as well as on the comparative risk assessment of alcohol and drugs [2][3][4][5].

\section{Expert work for WHO IARC}

Since 2007, Dr. Lachenmeier has regularly contributed to working groups of themonographs program of the World Health Organization's International Agency for Research on Cancer (IARC). At several meetings he was responsible as sub-group head for the exposure or epidemiology sections of the meetings. The contributions were included in the following IARC monographs and reports:

- Volume 96 (2010) Alcohol Consumption and Ethyl Carbamate

- Volume 101 (2012) Some Chemicals Present in Industrial and Consumer Products, Food and Drinking-water

- Volume 108 (2015) Some Drugs and Herbal Products

- Volume 116 (2018) Drinking Coffee, Mate, and Very Hot Beverages

- Volume 119 (2019) Some Chemicals That Cause Tumours of the Urinary Tract in Rodents

- Advisory Group to Recommend Priorities for the IARC Monographs during 2020-2024 (2019)

- Report of the Advisory Group to Recommend an Update to the Preamble to thelARC Monographs (2019)

\section{Productivity}

Dr. Dirk Lachenmeier has more than 400 articles in international refereed journals and books, including the Lance[ $]$, the Lancet Oncology [7][8][9][10][11][12] , the Lancet Gastroenterology \& Hepatology ${ }^{[13]}$, the Journal of the National Cancer Institute ${ }^{[14]}$, the International Journal of Cancer ${ }^{[15][16][17]}$, the British Medical Journa[18], BMC Medicine ${ }^{[19]}$, BMC Cancer[20][21], Addiction[2][22][23][24][25][26][27] and more than 100 other journals. According toGoogle Scholar (March 2020), the publications of Dr. Lachenmeier achieved 11.266 citations, his h-index is 56 and his i10-index is 199. The ten publications with the highest number of citations are Refs[11][28][29][5][30][22][31][32][33][34]. According to Laborjournal, Dr. Lachenmeier is listed among the highest-cited researchers in Germany in toxicology. For full publication list, see Research Gate.

\section{Awards}

Dr. Lachenmeier received the Award of the Fonds of Chemical Industry (1994) for his university-entrance diploma in chemistry. In 2005, he received the Bruno-Rossmann-Award of the Food Chemical Society for the study "Rapid 
screening for ethyl carbamate in stone-fruit spirits using FTIR spectroscopy and chemometrics"[35]. For his peer reviewing activity of more than 600 reviews according to $\underline{\text { Publons, }}$, Dr. Lachenmeier was among the top reviewers in cross-field (September 2019), top reviewers for agricultural sciences (September 2018), top reviewers in Germany (September 2017), top reviewers for agricultural and biological sciences (September 2017), top reviewers for pharmacology, toxicology and pharmaceutics (September 2017), sentinels of science: chemistry (September 2016), top reviewers for Germany (Jan 2016-Apr 2016), top reviewers for Publons (Oct 2014-Jan 2016).

\section{References}

1. Neue Methodenkombination aus dynamischer Festphasenextraktion, Gaschromatographie und Massenspektrometrie für den Einsatz in der forensisch-toxikologischen Haaranalytik . Dissertation, Universität Bonn. Retrieved 2020-3-13

2. Dirk W. Lachenmeier; Kerstin Schoeberl; Fotis Kanteres; Thomas Kuballa; Eva-Maria Sohnius; Jürgen Rehm; Is contaminated unrecorded alcohol a health problem in the European Union? A review of existing and methodological outline for future studies. Addiction 2011, 106, 20-30, 10.1111/j.1360-0443.2010.03322.x.

3. Dirk W. Lachenmeier; Jenny Leitz; Kerstin Schoeberl; Thomas Kuballa; Irene Straub; Jürgen Rehm; Calidad del alcohol producido en Europa ilegalmente o de forma no regulada: resultados del proyecto AMPHORA. Adicciones 2011, 23, 133-140, 10.20882/adicciones.156.

4. Peter Anderson; Virginia Berridge; Patricia Conrod; Robert Dudley; Matilda Hellman; Dirk W. Lachenmeier; Anne Lingford-Hughes; David Miller; Jürgen Rehm; Robin Room; et al.Laura SchmidtRoger SullivanTamyko YsaAntoni Gual Reframing the science and policy of nicotine, illegal drugs and alcohol - conclusions of the ALICE RAP Project. F1000Research 2017, 6, 289, 10.12688/f1000research.10860.1.

5. Dirk W. Lachenmeier; Jürgen Rehm; Comparative risk assessment of alcohol, tobacco, cannabis and other illicit drugs using the margin of exposure approach. Scientific Reports 2015, 5, 8126, 10.1038/srep08126.

6. Dirk W. Lachenmeier; Reducing harm from alcohol: what about unrecorded products?. The Lancet 2009, 374, 977, 10.1016/S01406736(09)61661-5.

7. Dana Loomis; Kathryn Z Guyton; Yann Grosse; Beatrice Lauby-Secretan; Fatiha El Ghissassi; Véronique Bouvard; Lamia Benbrahim-Tallaa; Neela Guha; Heidi Mattock; Kurt Straif; et al. Carcinogenicity of drinking coffee, mate, and very hot beverages. The Lancet Oncology 2016, 17, 877-878, 10.1016/s1470-2045(16)30239-x.

8. Yann Grosse; Dana Loomis; Kathryn Z Guyton; Fatiha El Ghissassi; Véronique Bouvard; Lamia Benbrahim-Tallaa; Heidi Mattock; Kurt Straif; Some chemicals that cause tumours of the urinary tract in rodents. The Lancet Oncology 2017, 18, 1003-1004, 10.1016/s1470-2045(17)30505-3.

9. Jürgen Rehm; Dirk W. Lachenmeier; Eva Jané-Llopis; Sameer Imtiaz; Peter Anderson; Evidence of reducing ethanol content in beverages to reduce harmful use of alcohol. The Lancet Gastroenterology \& Hepatology 2016, 1, 78-83, 10.1016/s24681253(16)30013-9.

10. Yann Grosse; Robert Baan; Béatrice Secretan-Lauby; Fatiha El Ghissassi; Véronique Bouvard; Lamia Benbrahim-Tallaa; Neela Guha; Farhad Islami; Laurent Galichet; Kurt Straif; et al. Carcinogenicity of chemicals in industrial and consumer products, food contaminants and flavourings, and water chlorination byproducts.. The Lancet Oncology 2011, 12, 328-329, 10.1016/s14702045(11)70088-2.

11. Yann Grosse; Dana Loomis; Beatrice Lauby-Secretan; Fatiha El Ghissassi; Véronique Bouvard; Lamia Benbrahim-Tallaa; Neela Guha; Robert Baan; Heidi Mattock; Kurt Straif; et al. Carcinogenicity of some drugs and herbal products.. The Lancet Oncology 2013, 14, 807-808, 10.1016/s1470-2045(13)70329-2.

12. Jonathan M Samet; Weihsueh A. Chiu; Vincent Cogliano; Jennifer Jinot; David Kriebel; Ruth M Lunn; Frederick A Beland; Lisa A. Bero; Patience Browne; Lin Fritschi; et al.Jun KannoDirk W. LachenmeierQing LanGérard LasfarguesFrank Le CurieuxSusan PetersPamela ShubatHideko SoneMary C WhiteJon WilliamsonMarianna YakubovskayaJack SiemiatyckiPaul A WhiteKathryn Z GuytonMary K Schubauer-BeriganAmy L HallYann GrosseVéronique BouvardLamia Benbrahim-TallaaFatiha El GhissassiBéatrice Lauby-SecretanBruce ArmstrongRodolfo SaracciJiri ZavadilKurt StraifChristopher P Wild The IARC Monographs: Updated Procedures for Modern and Transparent Evidence Synthesis in Cancer Hazard Identification. JNCl: Journal of the National Cancer Institute 2019, 112, 30-37, 10.1093/jnci/djz169.

13. Robert Baan; Kurt Straif; Yann Grosse; Beatrice Lauby-Secretan; Fatiha El Ghissassi; Véronique Bouvard; Andrea Altieri; Vincent Cogliano; WHO International Agency for Research on Cancer Monograph Working Group; Carcinogenicity of alcoholic beverages. The Lancet Oncology 2007, 8, 292-293, 10.1016/s1470-2045(07)70099-2.

14. M Matilde Marques; Amy Berrington De Gonzalez; Frederick A. Beland; Patience Browne; Paul A Demers; Dirk W. Lachenmeier; Tina Bahadori; Dinesh K. Barupal; Fiorella Belpoggi; Pietro Comba; et al.Min DaiRobert D DanielsCatterina FerreccioOleg A GrigorievYun-Chul HongRobert N. HooverJun KannoManolis KogevinasGérard LasfarguesReza MalekzadehScott MastenRobert NewtonTeresa NoratJane J PappasCamila Queiroz MoreiraTeresa RodríguezJulietta Rodríguez-GuzmánVikash SewramLauren ZeiseLamia Benbrahim-TallaaVéronique Bouvardlan A CreeFatiha El GhissassiJennifer GirschikYann GrosseAmy L. HallMichelle C TurnerKurt StraifMichael KorenjakValerie McCormackKaren MüllerJoachim SchüzJiri ZavadilMary K Schubauer-BeriganKathryn Z GuytonIARC Monographs Priorities Group Advisory Group recommendations on priorities for the IARC Monographs. The Lancet 
Oncology 2019, 20, 763-764, 10.1016/S1470-2045(19)30246-3.

15. Dirk W. Lachenmeier; Szidönia Gumbel-Mako; Eva-Maria Sohnius; Andrea Keck-Wilhelm; Evamaria Kratz; Gerd Mildau; Salivary acetaldehyde increase due to alcohol-containing mouthwash use: A risk factor for oral cancer. International Journal of Cancer 2009, 125, 730-735, 10.1002/ijc.24381.

16. Dirk W. Lachenmeier; Rolf Godelmann; Barbara Witt; Kerstin Riedel; Jürgen Rehm; Can resveratrol in wine protect against the carcinogenicity of ethanol? A probabilistic dose-response assessment. International Journal of Cancer 2013, 134, 144-153, 10.1002/ijc.28336.

17. Dirk W. Lachenmeier; Maria C. Przybylski; Jürgen Rehm; Comparative risk assessment of carcinogens in alcoholic beverages using the margin of exposure approach. International Journal of Cancer 2012, 131, E995-E1003, 10.1002/ijc.27553.

18. Dirk W. Lachenmeier; Jürgen Rehm; Perhaps not such a great threat to public health in the UK.. BMJ 2012, 344, e2251-e2251, 10.1136/bmj.e2251.

19. Jürgen Rehm; Dirk W. Lachenmeier; Robin Room; Why does society accept a higher risk for alcohol than for other voluntary or involuntary risks?. BMC Medicine 2014, 12, 189, 10.1186/s12916-014-0189-z.

20. Dirk W. Lachenmeier; Maria Cristina Pereira Lima; lan Cc Nóbrega; José Ap Pereira; Florence Kerr-Corrêa; Fotis Kanteres; Jürgen Rehm; Cancer risk assessment of ethyl carbamate in alcoholic beverages from Brazil with special consideration to the spirits cachaça and tiquira. BMC Cancer 2010, 10, 266-266, 10.1186/1471-2407-10-266.

21. Alex O. Okaru; Anke Rullmann; Adriana Farah; Elvira Gonzalez De Mejia; Mariana C. Stern; Dirk W. Lachenmeier; Comparative oesophageal cancer risk assessment of hot beverage consumption (coffee, mate and tea): the margin of exposure of PAH vs very hot temperatures.. BMC Cancer 2018, 18, 236-13, 10.1186/s12885-018-4060-z.

22. Dirk W. Lachenmeier; Fotis Kanteres; Jürgen Rehm; Carcinogenicity of acetaldehyde in alcoholic beverages: risk assessment outside ethanol metabolism. Addiction 2009, 104, 533-550, 10.1111/j.1360-0443.2009.02516.x.

23. Jürgen Rehm; Shalini Kailasapillai; Elisabeth Larsen; Maximilien X. Rehm; Andriy V. Samokhvalov; Kevin D. Shield; Michael Roerecke; Dirk W. Lachenmeier; A systematic review of the epidemiology of unrecorded alcohol consumption and the chemical composition of unrecorded alcohol. Addiction 2014, 109, 880-893, 10.1111/add.12498.

24. Fotis Kanteres; Dirk W. Lachenmeier; Jürgen Rehm; Alcohol in Mayan Guatemala: consumption, distribution, production and composition of cuxa. Addiction 2009, 104, 752-759, 10.1111/j.1360-0443.2009.02507.x.

25. Dirk W. Lachenmeier; Jürgen Rehm; Unrecorded alcohol: a threat to public health?. Addiction 2009, 104, 875-877, 10.1111/j.13600443.2009.02587.x.

26. Dirk W. Lachenmeier; Stephan G Walch; Commentary on Probst et al . (2018): Unrecorded alcohol use-an underestimated global phenomenon. Addiction 2018, 113, 1242-1243, 10.1111/add.14195.

27. Dirk W. Lachenmeier; Stephan G Walch; Commentary on Rehm et al . (2017): Composition of alcoholic beverages—an underresearched dimension in the global comparative risk assessment. Addiction 2017, 112, 1002-1003, 10.1111/add.13790.

28. IARC Working Group on the Evaluation of Carcinogenic Risks to Humans. Alcohol consumption and ethyl carbamate.; International Agency for Research on Cancer: Lyon, France, 2010; pp. 1-1424.

29. Dirk W. Lachenmeier; Rapid quality control of spirit drinks and beer using multivariate data analysis of Fourier transform infrared spectra. Food Chemistry 2007, 101, 825-832, 10.1016/j.foodchem.2005.12.032.

30. Dirk W. Lachenmeier; Safety evaluation of topical applications of ethanol on the skin and inside the oral cavity. Journal of Occupational Medicine and Toxicology 2008, 3, 26-26, 10.1186/1745-6673-3-26.

31. Jürgen Rehm; Fotis Kanteres; Dirk W. Lachenmeier; Unrecorded consumption, quality of alcohol and health consequences. Drug and Alcohol Review 2010, 29, 426-436, 10.1111/j.1465-3362.2009.00140.x.

32. Dirk W. Lachenmeier; Jürgen Rehm; Gerhard Gmel; Surrogate Alcohol: What Do We Know and Where Do We Go?. Alcoholism: Clinical and Experimental Research 2007, 31, 1613-1624, 10.1111/j.1530-0277.2007.00474.x.

33. Dirk W. Lachenmeier; Eberhard Humpfer; Fang Fang; Birk Schütz; Peter Dvortsak; Constanze Sproll; Manfred Spraul; NMRSpectroscopy for Nontargeted Screening and Simultaneous Quantification of Health-Relevant Compounds in Foods: The Example of Melamine. Journal of Agricultural and Food Chemistry 2009, 57, 7194-7199, 10.1021/jf902038j.

34. Dirk W. Lachenmeier; Eva-Maria Sohnius; The role of acetaldehyde outside ethanol metabolism in the carcinogenicity of alcoholic beverages: Evidence from a large chemical survey. Food and Chemical Toxicology 2008, 46, 2903-2911, 10.1016/j.fct.2008.05.034.

35. Dirk W. Lachenmeier; Rapid screening for ethyl carbamate in stone-fruit spirits using FTIR spectroscopy and chemometrics. Analytical and Bioanalytical Chemistry 2005, 382, 1407-1412, 10.1007/s00216-005-3285-2.

\section{Keywords}

unrecorded alcohol; NMR; biography; cannabis; food chemistry; risk assessment; toxicology; cancer 